Volume 6

Issue 1 January

Article 9

January 1979

\title{
The Social Construction of Disability
}

Arnold Birenbaum

St. John's University

Follow this and additional works at: https://scholarworks.wmich.edu/jssw

Part of the Social Work Commons

\section{Recommended Citation}

Birenbaum, Arnold (1979) "The Social Construction of Disability," The Journal of Sociology \& Social Welfare: Vol. 6 : Iss. 1 , Article 9.

Available at: https://scholarworks.wmich.edu/jssw/vol6/iss1/9

This Article is brought to you by the Western Michigan University School of Social Work. For more information, please contactwmu-scholarworks@wmich.edu.

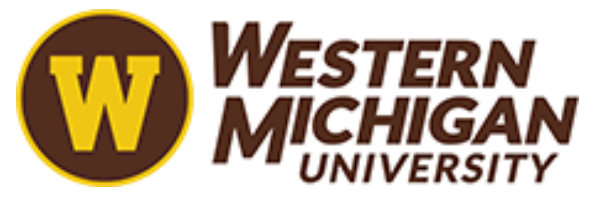


THE SOCIAL CONSTRUCTION OF DISABILITY

Arnold Birenbaum, Ph.D.

Associate Professor of Sociology

St. John's University

Jamaica, New York 11439

\begin{abstract}
This symbolic interactionist theory examines the structure of relationships between the disabled and the nondisabled through face-to-face interaction and the formation and participation in organizations which provide specialized services. Some propositions from handall Collin's Conflict Sociology (1975) create a framework for understanding the behavior of the disabled. Goffman's concept of career is used to examine the conditions under which various adaptive strategies are employed by the disabled to negotiate favorable definitions of self from their social communication. Finally, a symbolic interactionist explanation is outlined to account for the active and interested involvement of the nonhandicapped with the handicapped in getting the handicapped to accept their situation.
\end{abstract}

Persons who acquire a disability find themselves facing more than just an adjustment to a physical impairment or long-term illness which prevents them from walking as fast as other people, from riding horses, or holding a job in competitive employment. They are now regarded by others and even by themselves as being "different" and this difference is considered to be an undesirable one, affecting social interaction with others in such a way as to create a sense of awkwardness, embarrassment and confusion.

This problem of maintaining easeful face-to-face interaction between disabled and conventional members of society results, first, from the uncertainty produced in such situations as to what kinds of claims the disabled and the conventional person will make upon each other. If, for example, there is a young man with a prosthetic leg at a party, will he ask one of the young women present to dance? In turn, will one of the young ladies present ask that crippled young man to dance hoping to compensate for his "natural" shymess?

A second source of confusion and uncertainty remains in addition 
to that which may arise during such social occasions. Disability is rarely acquired in a conscious way, via an intentional misapplication of the recipes or formulaes that constitute the culture of a society. Moreover, it can hardly be said that the disabled are attempting to directly violate the rules for personal gain, to fulfill some disrespectable desire, or even to change the rules of the game. Rather, disability is acquired because the culture could not predict a fortuitous or accidental event or the onset of an illness so that it could be avoided. Thus, those who become disabled do so because they deliberately tried to follow the rules and were let down by those very rules. Acquiring a handicapping condition involves little intentional choice and can be conceived of as the crystallization of involuntary deviance into roles now performed by previously voluntary conformists. Since it is a competent person who now has become disabled the very rules which define competency are now called into question. Moreover, since this disabled person is still psychologically competent, he may start to question these rules since they proved to be unreliable. How is it that rebellion is a rare adeptation among the disabled?

An important use of questions in theory formation is to focus on the need to develop an adequate explanation for what might appear to be obvious. Starting with an effort to account for a lack of rebellion among the disabled helps us to see how new definitions of self are acquired by the disabled person through contact with the nonhandicapped and with organizations created to provide services to the handicapped.

Goffman's concept of a "moral career," provides a useful way of sensitizing the observer to factors which influence the individual's emergent definition of the situation and of the self. The term moral career is defined by Goffman as
- . any social strand of any person's course through life. The perspective of natural history is taken: unique outcomes are neglected in favor of such changes over time as are basic and common to the members of a social category, although occurring independently to each of them (1961: 127).

The concept of career allows the student of social behavior to link the disabled to institutions which are established to serve them, ongoing memberships in collectivities, and the reactions of the disabled to their situation. Strategies for maintaining favorable definitions of self may be considered as important as finding needed services.

An explicit set of assumptions about human nature and communication 
between human beings will help to show how the new career thrust on to the handicapped create certain conditions which do not exist for other people. A formal set of postulates derived from the merging of the interactionist and conflict perspectives in sociology have been articulated by Randall Collins. Much of the subsequent discussion about the social construction of disability-as an answer to why the disabled do not rebel-can be derived from these postulates.

I. Each individual constructs his own subjective reality.

II. Individual cognition is constructed from social commications.

III. Individuals have power over each other's subjective reality (from I and II).

IV. Each individual attempts to maximize his subjective status to the degree allowed by the resources available to himself and others he contacts.

v. Each individual values highest what he is best at, and attempts to act it out and communicate it as much as possible.

VI. Each individual seeks social contacts which give him greatest subjective status, and avoids those in which he has lowest status (from III, IV and V).

VII. Where individuals' resources differ, social contacts involve inequalities in power to define subjective reality.

VIII. Situations in which differential power is exercised, and withdrawal is not immediately possible, inplicitly involve conflict (from IV and VI).

(Collins, 1975: 73).

It follows then, from the last three postulates, that the moral career of the disabled person is shaped by recurrent social situations which either reinforce his capacity to rebel or makes rebellion an unlikely outcome. In discussing the social construction of disability, the focus of this paper is on the moral career of the disabled as developed at the points of contact with the family, community and agencies devoted to serving the handicapped. At these points of contact, the determinants of behavior specified in postulate VI can help to account for the prevention of the emergence of the social conditions specified in postulate VIII. In effect, by being capable of responding 
to the social communications given off by others through anticipation of stigma, the disabled individual of ten avoids conflict. At the same time he avoids contact with others who are similarly situationed and therefore a potential source of alternative social communications upon which to build a new social identity.

\section{THE SOCLAL SELF AND DISABILITY}

An important assumption in any discussion of the social construction of disability is the social competency of the disabled. Being a fully competent member of society includes a recognition of the meaning of membership and competency. This reflexiveness takes the form of a sense of what a member must possess, and who is to be allowed to participate in particular situations (Goffman, 1963: 2). Alternatively, knowledge of what it means to be a nonmember is part of the general role of a member. These rules of identity, or constitutive norms of social life, are acquired relatively early in life. Children will observe out loud that "the man sitting in the next seat has no arm in his sleeve" and parents will reward children for being so observant, even when they admonish them for being overly rocal in public.

Violations of these norms of social identity are events that those who are disabled have to manage to deal with, particularly in the company of conventional people who are strangers to the handicapped person. Every transgression of these norms in the form of a discrediting discrepancy between an actor's virtual (or expected) and actual identity calls into question the validity of these rules, since those who cannot sustain competency may still seek to do so (Goffman, 1963: 5). Then, the everyday grounds for judging others and oneself are made problematic, since actors are uncertain about the kinds of claims that might be made by either the discrepant or the conventional individuals. Thus, such encounters threaten the beliefs of all present in the culture in two ways: (1) The one to one correspondence of the social and the natural order-that is, the correspondence between the way things are anticipated and the way they actually turn-is called into question; (2) then, if one or both fail to take the discrepancy from cultural expectations into account in their relationship, then they call into question the conventional character of that person or their relationship, suggesting to others a kind of joint or dual madness.

While disability may be unpredictable, according to the recipes we use in everyday life, every culture provides a general idea to the members of society concerning what it must be like to possess such a handicap and even provides a rank ordering of various impairments. 
This uniformity in response to disability provides a third source of uncertainty in relations between those with handicaps and the nonhandicapped since the nonhandicapped do not want to reveal to the handicapped the negative attitudes which they hold toward the disability. Indeed, the pervasiveness of the cultural conceptions on disability is so great that even children who were born with physical disabilities will share these negative values about this condition (Richardson, et. al., 1961). In social psychological studies conducted among children with physical disabilities, they were more likely to choose pictures of children without handicaps as preferred playmates to those where the identical child was shown in different pictures to have five separate physical handicaps (Richardson, et. al.., 1961).

The amount of self-deprecation and self-hatred experienced by those with physical disabilities should not be underestimated as an important source of keeping them in line, particularly when they were and in so many ways, still are, voluntary conformists in society. Still, there does seem to be one predictable way of responding to this fate. It can be conceived that there are three ways of adapting to the stigma of physical disability. Some who bear a stigma attempt to embrace their role and do not attempt to convey an image of normality, but seek to make their impairment the central focus of their lives. Others seek to erase all information about their stigma and seek to convey the impression of being unsoiled. Finally, others move between these two extreme points and seek to perform many conventional social roles with their differentness being occasionally manifested by their association with others who are also stigmatized. This last adaptation may be regarded as an effort to "normalize" one's deviance (Davis, 1964) so that it does not become obtrusive in all social situations but is taken into account in all ongoing social relationships. Embracement of the stigma is less likely to occur in the case of physical disability than in the case of minority group membership because rarely does a counterculture exist which insists that the stigma is a badge of honor, rather than a discrediting discrepancy. Accordingly, when revaluation of the discrepancy is possible, then the use of metaphor to describe their situation will be borrowed from the language of minorities, particularly when the stigma is biographical in nature. While homosexuals do claim that being gay is good and one ought to be proud of one's sexual tastes, those with physical handicaps do not make the same assertions about their discrepancy. They may seek to get nonhandicapped people to regard them in a more accepting way by insisting on the use of certain labels for their condition, but the basis of their problem and their plea for acceptance is still the unintentionally acquired character of the impairment to their physical functioning. 
Thus, there is a strain toward "normalization" among the disabled since this is one way of avoiding being regarded as more deviant than they are now so regarded. Denial and embracement might both be regarded by others as signs of severe psychological disturbance, perhaps brought on or precipitated by the acquisition of physical disability, but something that prevents the person from recognizing either his physical limitations or his other capacities; from becoming aware of the obtrusiveness or lack of it produced by the disability when it comes to social interaction; from neglecting or paying an inordinate amount of attention to his other responsibilities, i.e., being an employee, a wife, a father, etc. As conventional members of society, we question the competency of a person who fails to deal with "reality" or who denies our theories of the disadvantages to being disabled. The middle road is regarded as the wisest course because it confirms the culture's theories about disability:

The general formula is apparent. The stigmatized individual is asked to act so as to imply neither that his burden is heavy nor that bearing it has made him different from us; at the same time he must keep himself at that remove from us which ensures our painlessly beins able to confirm this belief about him. Put differently, he is advised to reciprocate naturally with an acceptance of himself and us, an acceptance of him that we have not quite extended him in the first place (Goffman, 1963: 122).

In following this formula, the disabled person, either consciously or unwittingly, takes part in a process of restoration of the belief in those cultural formulae which he followed and which failed him. This process begins with a recognition and acceptance of the stigma by the disabled person, promoting the routinization of deviance into what may be regarded as a "normal appearing round of life" (Birenbaum, 1970) (Birenbaum, 1971). In so doing, the disabled person not only removes uncertainty and strain from his life, but restores his belief and others' in the cultural formulae. How society handles the problem of culturally induced psychological strain is made possible by the victimization of someone who was previously regarded as a competent member of the social order (Garfinkel, 1956) and yet this victimization is controlled in its intensity and scope so that the stigmatized person and the normal individual are able to establish new shared meanings, thereby creating reciprocal models of response between the two parties.

It can be seen that the disabled or handicapped person enters into 
negotiation with conventional persons to acquire needed resources, including favorable definitions of self. The moral career of the disabled can encourage acquired differences in personality and role performance. Certain kinds of affiliations and agencies devoted to helping persons so characterized have extensive impact on their lives. Just as certain relevant others will support voluntary deviance, as in the case of those who live off crime, there are contacts among those who are similarly disabled, producing support for certain styles of life and rejecting others. Similarly, courts and prisons influence considerably the life chances of the criminal while hospitals and rehabilitation programs have a similar affect on many of the important career choices made by the disabled.

\section{DISABILITY AND LIFE CHANCES}

Disability may be acquired in early childhood, even at birth, and parental response to a disabled child may be quite different than to a normal child. Moreover, it is very rare that a parent will have had any experience at all with disability when the child is born and cannot be a very good model of how to adapt to it for the child. Often the parents feel very guilty, at least during the first few months after finding out about the child's condition (Birenbaum, 1969). The presence of a handicapped child in the family may lead to a redefinition of the child as one who is constantly "sick" and requiring a certain kind of care and attention. This perspective of ten has a correlate to it: That the child does not require other kinds of social and intellectual stimulation that one would give to a nonhandicapped child. In such cases fewer demands are placed on children with disabilities while other children in the family are expected to perform at a very unrealistic level of competence (Richardson, 1969: 1050). Inevitably, the unchanged developmental capacities of the handicapped child remain overlooked in order to treat the child as a sick child. Such overcompensating efforts may also involve endless searches for cures or at least a more favorable diagnosis. As a result the child develops a sense of self which may indeed be based on an appropriate response but to a set of unusual expectations.

Children with physical disabilities will inevitably learn how the culture evaluates his handicap no matter how protective parents might be. Self deprecation or low self esteem, as mentioned earlier, seems to be a common pattern in these cases, exacerbated in those instances when there are no alternative sources of support or claims of competency that can be made by the child. A child who is treated as being sick may never be given the opportunity to prove himself and his impairment may become the central focus in his life, resulting in an embracement 
of the role, rather than a normalization.

While most physical disability does not involve an actual disfigurement, it alters the person's body sufficiently to present a discrepancy between what is expected and the actual image the person presents. Physical appearance seems to be a very important aspect of face-to-face interaction at all times in the life cycle. It is particularly important during adolescence as a way of classifying and rating others and oneself. It is likely, therefore, that toleration of such differences would be lowest among this age cohort and consequently, the physically disabled teenager would suffer a substantial reduction in self esteem.

Physical appearance is a basic source of information about others, particularly during first encounters between people. A person with a disability would then need to have a wide array of social skills available in order to offset the uncertainty and potential derogation during such an encounter. Even when such a repertoire of social skills existed, the tendency among the nonhandicapped to avoid interaction with the handicapped is very great. Thus, the lack of social skills possessed by a disabled person may result from a lack of opportunity to develop them, rather than an unwillingness or an incapacity to do so. Often, those who seek out contact with the handicapped are social isolates themselves and hardly make good models for disabled children or adolescents (Richardson, 1969: 1055).

One adjustment to the presence of disability may be a kind of overconformity (Merton, 1959) to other rules concerning identity, as a way of giving the impression to others that one's handicap has not led to a general neglect of personal appearance. The disabled person may appear less "interesting" to others or dress in less flamboyant colors than others as a way of saying that they can uphold some rules if not all rules of identity. Accordingly, less visible aspects of identity may also take on a conforming quality. Political and religious attitudes may be very orthodox, least they frighten away a potential friend. Overconformity may be an inevitable response of those who must work so hard to be regarded as acceptable in various social situations. Like the immigrant who becomes a superpatriot, the disabled may become supercritical of individual differences, and in so doing, demonstrate a loyality to a code of demeanor to which few pay such strict attention and hardly any live and die by anymore. Formalization of relationships on the part of the physically disabled may not only be a way of dealing with uncertainty but also a way of receiving support for their claims to be treated with respect. 
Each person with a physical disability also lives a life as a deviant insofar as he belongs to collectivities made up exclusively of those who are similarly situationed and to those made up predominately of nonhandicapped persons. This dual membership among one's own kind and among the others enables him to lead a "normal appearing round of life," receiving support from each collectivity for the particular kinds of claims that he seeks to make in each world. The person who is successful in this adaptation seeks a careful balance between the world of the stigmatized and the world of the normal. To some extent this balance is predicated on the person's participation in the social organizations and culture of the world of disability. The orderliness found in this culture creates a useful parallel of conventionality from which one can convey impressions of managing an intolerable situation, thereby helping to reduce the now of ten unpredictable nature of the conventional social order. Moreover, when accepting the primacy of conventional social roles, those with stigmas assiduously aroid overinvolvement in the world of the stigmatized thereby minimizing the extent to which normals will regard them as even more deviant, even in the presence of other disabled individuals.

It is expected that involvement with others in such organizations devoted to helping the disabled will be much greater when the disability is first acquired than it will be at a later point in time. This is due to the newmess of the deviant role now being performed but also because of the relief from uncertainty provided by organizations of others who have gone through the same social transformation. Indeed, at this point there may actually be a deviance "avowal" as a way of dealing with the problem or uncertainty and also as a way of explaining what has happened to produce this unexpected and undesired condition (Turner, 1972). Learning new explanations help to reduce the sense of self-blame when the discrepency with conventional persons is recognized (Birenbaum, 1969: 379). Some disabled persons who contimue to embrace the deviant role will become formal leaders of these organizations, leading a life devoted to getting nonhandicapped persons to be more sympathetic to the handicapped, to get greater subsidization from the government for retraining and rehabilitation, etc. By performing such conventional lobbying activities for such unusual organizations they demonstrate a "normal appearing round of life" not in spite of their handicap alone, but also because of it as well. In a personal sense, those who perform these leadership roles represent a continuous round of impression management, as they move from embracement to normalization to denial of the impact of the disability on their competency all in a single day, all in a single effort to increase the effectiveness of their organizations. Keeping these organizations alive also enables them to keep 
their positions going and their style of adaptation; being identified as a symbol of disability and adjustment may be a small price to pay for the larger success of being able to direct such important organizations.

Not all the people who hold the major posts of these organizations are handicapped themselves. During the past fifteen years, mainly through the innovative programs of the various branches of the Department of Health, Education and Welfare, there has been a vast proliferation of the fields of rehabilitation and physical medicine. Amid the branches and institutes of this federal agency, and with the advent of the Poverty Program and its incorporation under the Office of Economic Opportunity, there has come into being a vast organizational network of "caretaker" agencies to perform the social control functions associated with disabilities: For if the initial premise is correct, that voluntary conformists who followed all the recipes were then rewarded with suffering, disappointment and derogation, then they remain a potential threat to that culture and a source of discontent in the society. A new set of careers is created for those in the areas of psychology, social work, prosthetics, physical medicine, etc., based upon the belief that they can help the adjustment and/or rehabilitation of the various segments of the American population who fall into the general category of involuntary deviants.

The early 1960's marked a rapid increase in monies available not only for research but for the development of "pilot" programs in many areas of disability, including mental illness and mental retardation. These agencies supported both innovative programs and provided capital grants to establish new diagnostic clinics, rehabilitation centers, sheltered workshops for vocational rehabilitation and/or the creation of permanent opportunities for noncompetitive employment in voluntary organizations. Many of these programs were modeled after such efforts for the blind, particularly in the area of vocational rehabilitation and workshops, which had been established in the 1930's, again with federal subsidization in the form of exclusive contracts to these facilities to provide mops and brooms assembled by the blind (Scott, 1969). Similar efforts gained acceptance after World War II as a way of aiding returning disabled veterans.

Rehabilitation is a process which does not begin and end when the disabled person has developed some way of managing the problems associated with functioning with a physical handicap or even with its stigma. Organizations and their agents seek to impose their view of the particular handicap upon the person who possesses it, ". . .determining the form which deviance will take" (Scott, 1965: 135). Organizations and agencies possess a perspective on disability which 
in no small way affects the possible adaptations available for the handicapped and the extent to which they can lead independent lives. These agencies carry on the following activities:

\author{
First, they specify what personal attributes shall \\ be called handicaps. Second, they seek to identify \\ who conforms to their specifications. Third, they \\ attempt to gain access to those whom they call \\ handicapped. And fourth, they try to get those to \\ whom they gain access to change their behavior \\ so as to conform more closely to what the \\ institutions believe are their potentialities \\ (Freidson, 1965: 71).
}

Since many of these agencies provide important services to their clients and thus make available a great deal in the way of resources, they are able to get the disabled person to accept a certain definition of himself, or at least say so in the presence of rehabilitation workers. Attitudes of the disabled are of central importance in the perspectives on handicaps held by such workers: For if they are to gain "acceptance" of the handicap, if not embracement, and continued use of the agency for services by the disabled person, then they must be certain that they will not question their fate or be socially disruptive. The segregated character of these agencies-the fact that they are specialized by disability when the help that is sought may have little to do directly with their physical impairment-promotes the development of a sense of performing a deviant role. In turn, lack of contact with those who are not handicapped or who have nothing to do with the organized world of rehabilitation, reinforces this sense of differentness since one is judged and judges oneself by the company one keeps.

Thus, despite the general recognition in the culture that the acquisition of physical disability is undesired and that the person who has one is not responsible for it, members of the community permit and encourage the physically disabled person to take on a role built around the disability, but more importantly, one which is regarded as creating a spoiled identity for that unlucky person. One may raise the question why the lay community permits and encourages these specialized agencies to promote this discreditation of one who was a voluntary conformist up to this unfortunate and fortuitous event. Do they not realize that they may be next, since they have no recipes to prevent such an undesired event from occurring?

The process of transformation from a voluntary conformist to an 
involuntary deviant reveals a profound underlying concern, the need for a continuous restoration of the cultural and social order when threatened by anomalous situations, when things do not go according to the way they were supposed to be. Conventional actors reaffirm their belief in the cultural formulae by proferring a stigma which redefines those discrepant individuals' past and future performances as no longer accountable to that set of rules. The stigmatized are "removed" from the conventional social order, and in so doing, the conventional members re-establish the primacy of such cultural directives as "competent people will avoid accidents." Disability, in itself, so long as it is recognized as being outside the conventional social order, does not threaten the members belief in the cultural formulae. More importantly, it confirms them as everyday grounds for the judgment of normality; failure to do so would call into question their own normality. The reaffirmation of the validity of the cultural order does not end with conventional members of society. Stigma profferment not only offers the handicapped a new identification, albeit a deviant one; they accept it because their belief in the cultural formulae has been threatened too.

\section{CONCLUSION}

A rather conservative outcome is suggested by this discussion of the social construction of disability. Yet the disabled have only recognized their differentness when they have been able to get others to recognize their humanity. Their skill in establishing interpersonal relationships provides an insight into the way we can be, enriching our understanding of the fluidity of social life and the alterability of social structure. The need to work to get what people need, despite the reality of appearances, makes possible the acquisition of human dignity and the development of a society in which it is fostered and sustained.

\section{REFFERENCES}

Birenbaum, A.

1969 "How mothers of mentally retarded children use specialized facilities." The Family Coordinator 18 (October): 379-385.

1970 "On managing a courtesy stigma." Journal of Health and Social Behavior 11 (September): 196-206.

1971 "The recognition and acceptance of stigma." Sociological Symposium (Fall) 1971: 15-22. 


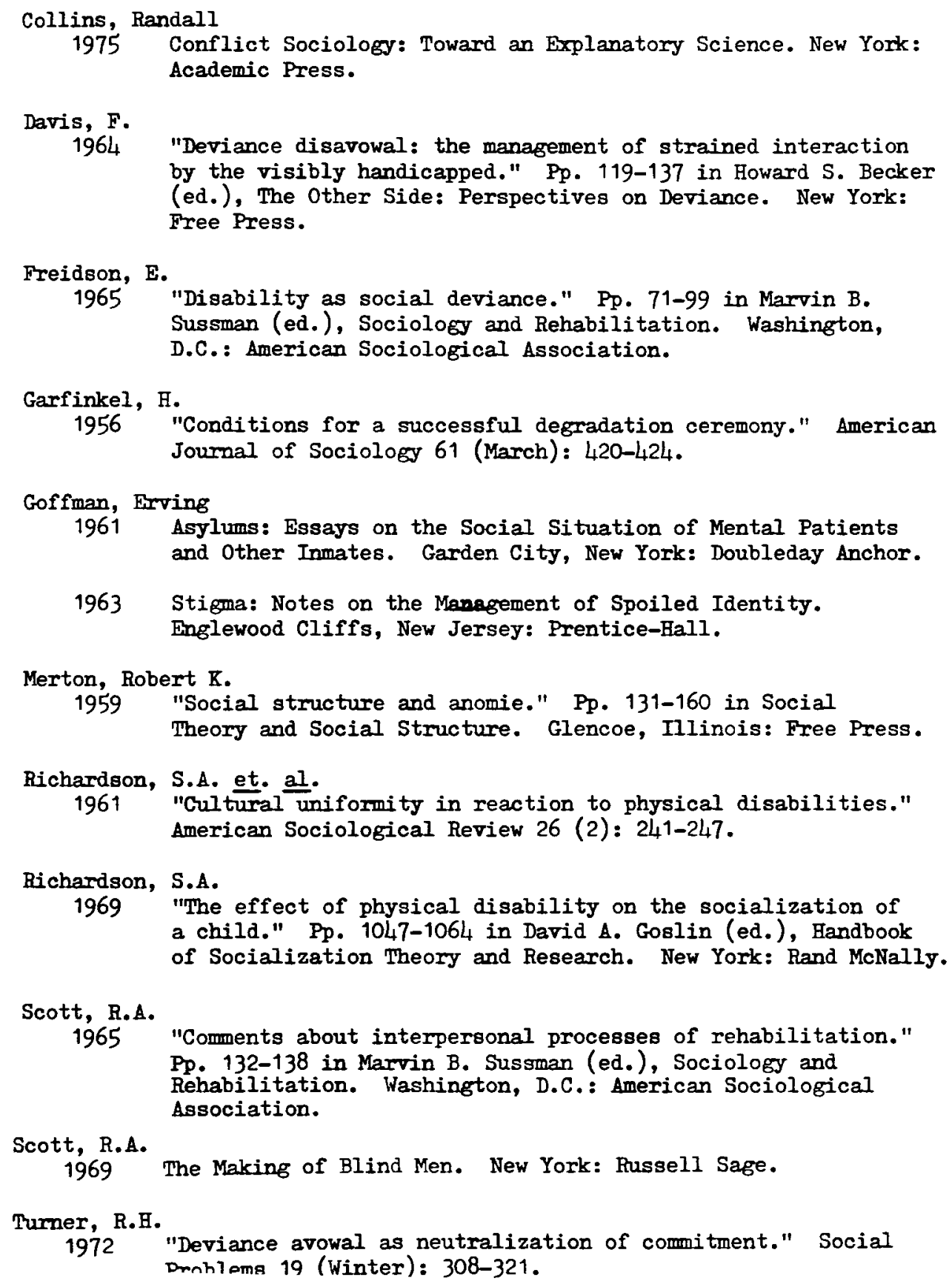
by the visibly handicapped." Pp. 119-137 in Howard S. Becker (ed.), The Other Side: Perspectives on Deviance. New York: Free Press.

Freidson, E.

1965 "Disability as social deviance." Pp. 71-99 in Marvin B. Sussman (ed.), Socioloey and Rehabilitation. Washington, D.C.: American Sociological Association.

Garfinkel, H.

1956 "Conditions for a successful degradation ceremony." American Journal of Sociology 61 (March): 420-424.

Goffman, Erving

1961 Asylums: Essays on the Social Situation of Mental Patients and Other Inmates. Garden City, New York: Doubleday Anchor.

1963 Stigma: Notes on the Management of Spoiled Identity. Englewood Cliffs, New Jersey: Prentice-Hall.

Merton, Robert $\mathrm{K}$.

1959 "Social structure and anomie." Pp. 131-160 in Social

Theory and Social Structure. Glencoe, Illinois: Free Press.

Richardson, S.A. et. al.

1961 "Cultural uniformity in reaction to physical disabilities." American Sociological Review 26 (2): 241-247.

Bichardson, S.A.

1969 "The effect of physical disability on the socialization of a child." Pp. 1047-1064 in David A. Goslin (ed.), Handbook of Socialization Theory and Research. New York: Rand McNally.

Scott, R.A.

1965 "Comments about interpersonal processes of rehabilitation." Pp. 132-138 in Marvin B. Sussman (ed.), Sociology and Rehabilitation. Washington, D.C.: American Sociological Association.

Scott, R.A.

1969 The Making of Blind Men. New York: Russell Sage.

Turner, R.H.

1972 "Deviance avowal as neutralization of commitment." Social Denhlema 19 (Winter): 308-321. 